\title{
Integration of Hybrid PV/Wind Generation System Using Fuzzy MPPT in Grid Connected System for Remote Area
}

\author{
Soedibyo, Thohaku Abdul Hadi, Hadyan Perdana Putra, Heri Suryoatmojo, Mochamad Ashari \\ Electrical Engineering Department, Institut Teknologi Sepuluh Nopember, Surabaya-East Java. Indonesia
}

\begin{abstract}
Photovoltaic and wind are renewable energy resources that widely used and grow rapidly in fulfilling electricity demand. Powers from both technologies depend on sunlight intensity and wind speed. For small scale power generation, DC voltage from both technologies is low and requires step-up converter to raise DC voltage ratio before converted into AC voltage. To optimize this system, step-up converter must have high ratio and efficiency to a distance of wide voltage input. This paper proposed an operation simulation and arrangement of DC-DC converter along with DC-AC from hybrid source PV-Wind which integrated to grid utilities without using storage device. High Gain Integrated Cascade Boost (HGICB) is DC-DC converter that has quadratic voltage ratio and used in this research. Then DC link connected to Voltage Source Inverter (VSI) which interconnected with utility grid and controlled by current control method. The total installed capacity of hybrid source is $4.4 \mathrm{~kW}$. Wind turbine uses PMSG along with full bridge rectifier. To maximize and stabilize the generated power, MPPT fuzzy is used. Result from the simulation shows that converter capable to maintain maximum power whether from PV and wind turbine which canalized to utility grid in various irradiation condition, wind speed, and grid load alteration.
\end{abstract}

\section{Introduction}

In this modern era, electricity becomes one of basic needs of mankind. However, there are still many places around the world which have no access to electricity. International agencies report that more than $20 \%$ of world's population have no access to electricity [Energy 2009]. Generation of electricity through renewable energy sources such as solar and wind could be potential options for these remote places. Solar and Wind are renewable energy sources which are easily found in nature and also kind of alternative energy that develop in a rapid speed. To convert energies from solar and wind, photovoltaic (PV) and wind turbine is used. PV and Wind turbine has a characteristic of power which depends on solar irradiation and wind speed based on geographical areas. This paper presented a control methodology of hybrid small scale PV/Wind energy system that use a fuzzy logic controller (FLC) to extract the maximum power point tracking (MPPT) in different solar irradiation and wind speed.

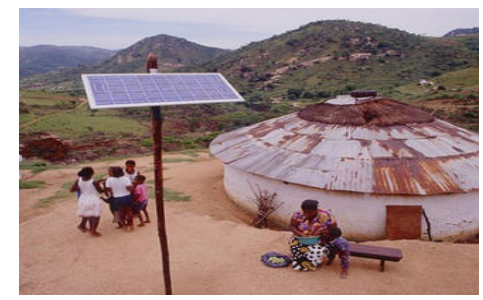

Fig. 1 A remote village in Nepal with small scale wind turbine (University of Canterbury, New Zealand, 2013)

This paper discuss simulation and analysis of the generation process and power conditioning unit (PCU) of Photovoltaic (PV) and Wind Turbine (WT) that is connected to the three phase low voltage electricity grid system $(380 \mathrm{~V})$. The capacity of the sources used is $2.2 \mathrm{kWp} \mathrm{PV}$ and $2.5 \mathrm{~kW}$ PMSG (Permanent Magnet Synchronous Generator) - WT power rating. The Modelling of hybrid PV/Wind as well as integrated power electronics components in grid connected system is simulated using MATLAB/Simulink.

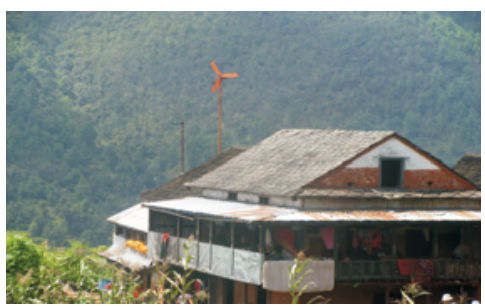

Fig. 2 A remote village with small scale photovoltaic (bravenewclimate.com)

\section{Methodology}




\subsection{Photovoltaic, Wind Turbine, Grid System Modelling}

This step is modelling small scale PV and Wind Turbine and its DC/DC converter to show the characteristic of power at different solar irradiation and wind speed in grid interconnecting system.

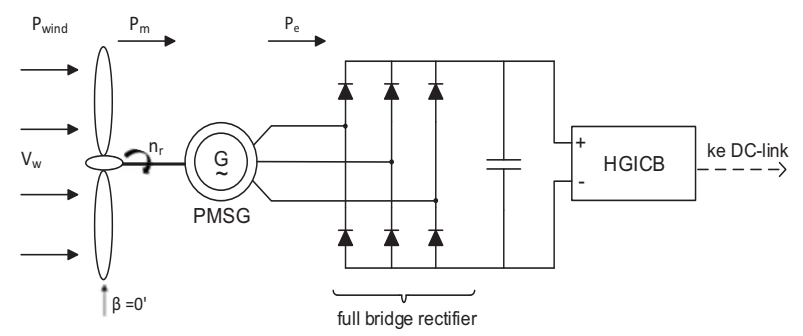

Fig. 3 Equivalent circuit of photovoltaic cell

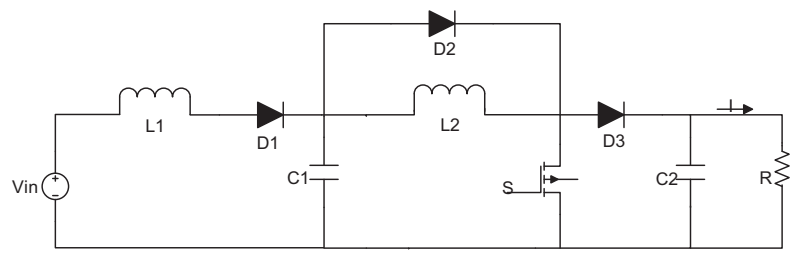

Fig. 4 Schematic of wind turbine system

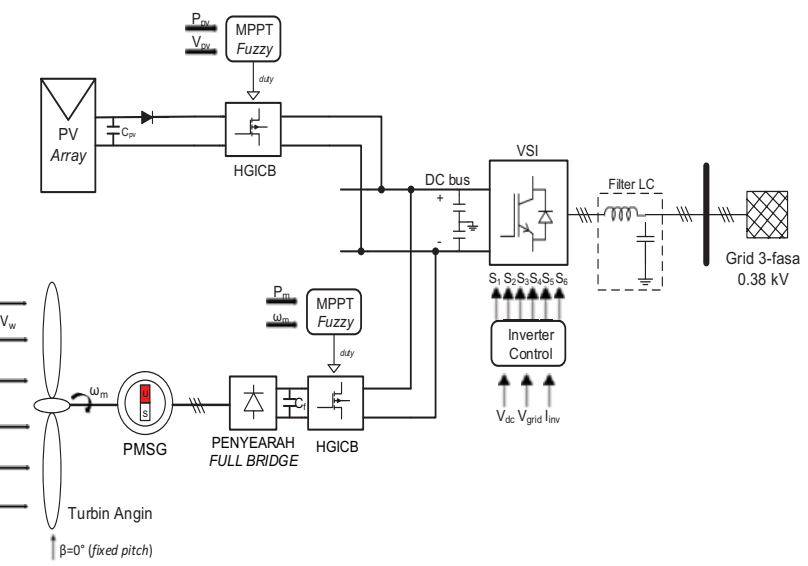

Fig. 5 Schematic of HGICB circuit

Figure 6 shows the schematic diagram of hybrid $\mathrm{PV} /$ Wind that connects to the grid through a common DC bus at the inverter. The solar PV with the capacity of 2.2 $\mathrm{kWp}$ and PMSG Wind Turbine with the capacity of 2.5 $\mathrm{kW}$ connects to the DC-DC converter that have a MPPT function. The inverter is transformerless, so the DC-DC converter use a High Gain Integrated Cascade Boost (HGICB) topology which have a high ratio to bring the output voltage of PV and WT to DC common bus voltage. The MPPT was applied to these HGICB converter using fuzzy logic controller (FLC) that achieve the maximum power from any irradiation and wind speed condition. The DC bus voltage is controlled by the inverter that it can in stable value. The inverter is VSI and use a fast decoupled current control to get synchronization with the utility grid. LC filter is use to damp the harmonic output voltage and current so its value must not exceed from the grid requirement.

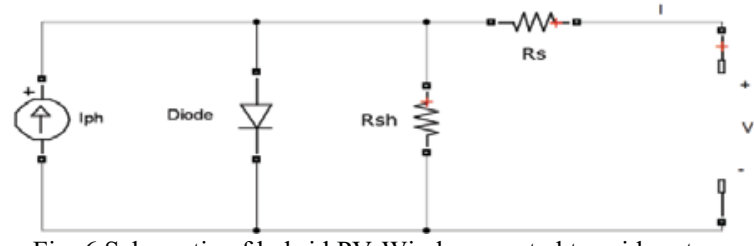

Fig. 6 Schematic of hybrid PV-Wind connected to grid system

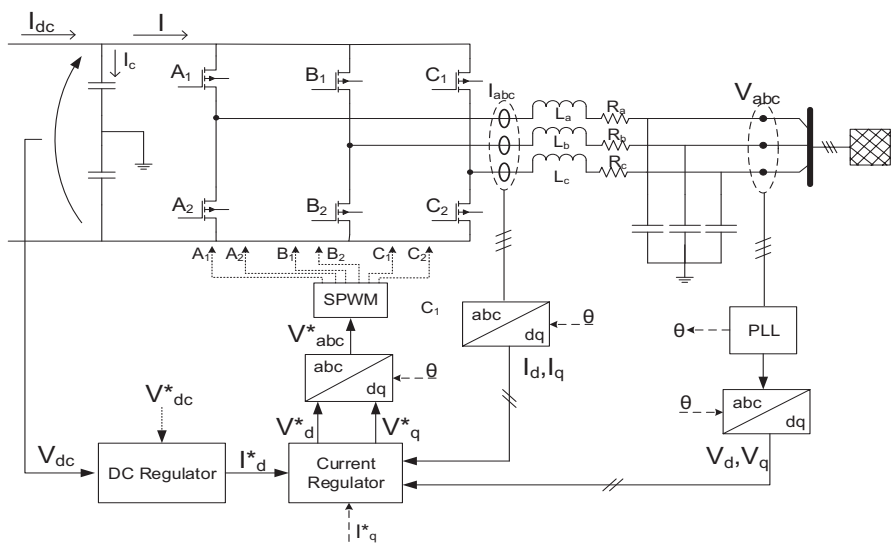

Fig. 7 Current control scheme of the VSI

\subsection{Design a Fuzzy Logic Controller (FLC) to Achieve the Maximum Power}

This step is designing a control of maximum power point tracking (MPPT) using fuzzy logic. Then show its work in different solar irradiation and wind speed. The MPPT was designed for two DC-DC converter both for solar PV and wind turbine. Figure and table below shows the fuzzy control scheme, membership function and rule base of MPPT control for PV and wind turbine respectively.

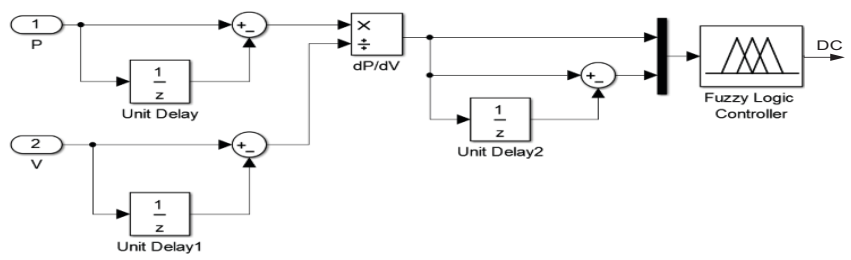

Fig. 8 PV MPPT fuzzy control scheme

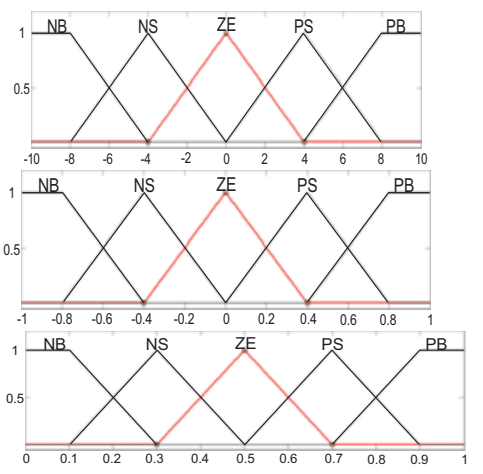

Fig. 9 Membership function of error (e), delta error (de) and duty cycle (duty) as a input - output FLC for PV MPPT 
TABLE I

RULE BASE FUZZY LOGIC IN PV MPPT

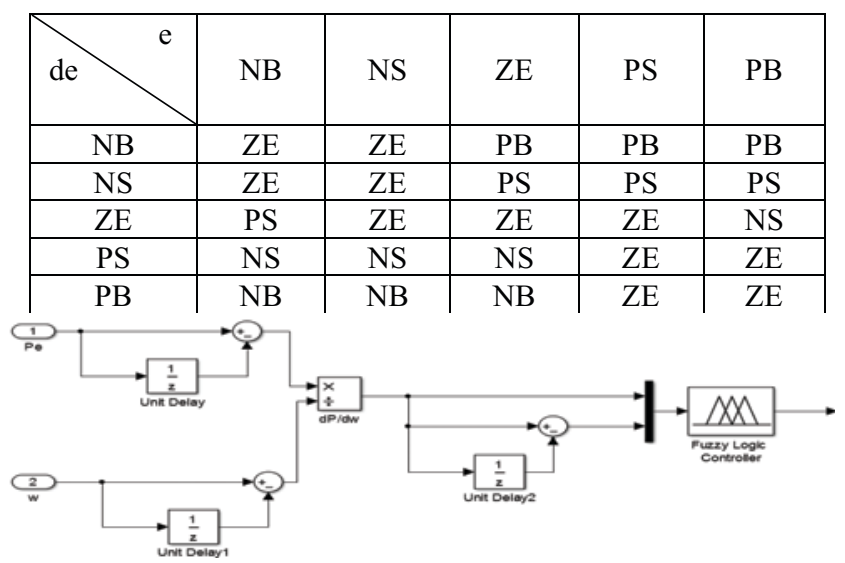

Fig. 10 wind turbine MPPT fuzzy control scheme
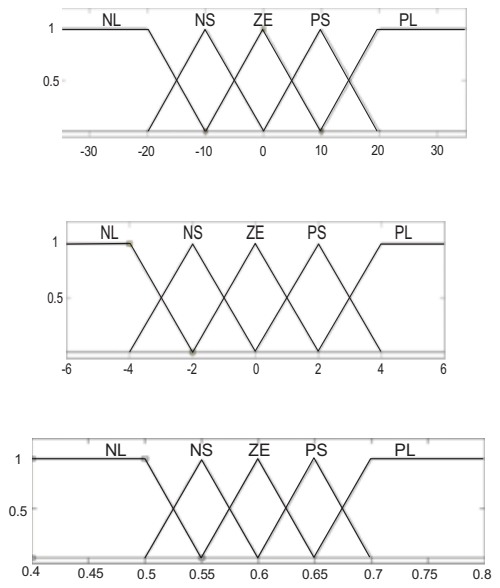

Fig. 11 Membership function of error (e), delta error (de) and duty cycle (duty) as a input - output FLC for WT MPPT

TABLE II

RULE BASE FUZZY LOGIC IN WIND TURBINE MPPT

\begin{tabular}{|c|c|c|c|c|c|}
\hline NL & NL & NS & ZE & PS & PL \\
\hline NS & NL & NL & NS & NS & ZE \\
\hline ZE & NS & NS & ZE & PS & PS \\
\hline PS & NS & ZE & PS & PS & PL \\
\hline PL & ZE & PS & PS & PL & PL \\
\hline
\end{tabular}

\section{Result}

The result shows that hybrid $\mathrm{PV} /$ Wind generation system can achieve the maximum power at different solar irradiation and wind speed. The maximum power is controlled by using fuzzy logic applied in its DC/DC Converter to set the duty cycle of the High Gain Integrated Cascade Boost (HGICB) converter. Output of HGICB converter is connected to Voltage Source Inverter (VSI) using voltage and current regulator. Thus, the DC-link voltage is kept constant at $650 \mathrm{~V}$. Output of VSI is connected to 1 MVA grid.
Using fuzzy logic, the duty cycle of DC/DC converter is set to reach the maximum power. The input of fuzzy logic controller is error (e) and change in error (de). In PV system, the error is changed in power divide by change in voltage.

$$
e=\frac{\Delta P}{\Delta V}=\frac{P(t)-P(t-1)}{V(t)-V(t-1)}
$$

But in Wind turbine system using PMSG in variable speed-fixed pitch, the converter used are 3-phase full bridge uncontrolled rectifier and HGICB converter. The fuzzy logic design of wind turbine is different from PV system. The input of fuzzy logic is changed in mechanical power $(\mathrm{Pm})$ divide by change in rotational speed $(w)$.

$$
e=\frac{\Delta P m}{\Delta w}=\frac{P m(t)-P m(t-1)}{w(t)-w(t-1)}
$$

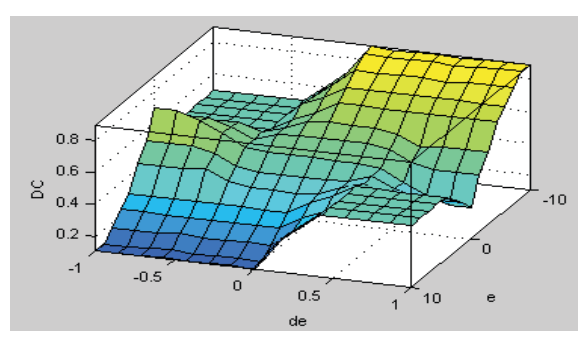

Fig. 12 A surface of fuzzy logic MPPT for PV system

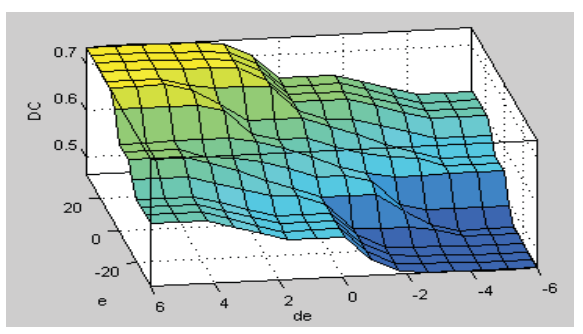

Fig. 13 A surface of fuzzy logic MPPT for Wind turbine system

There are two (2) scenarios to experimenting the Hybrid PV/Wind with the control scheme above. First is the hybrid system is tested to connects to the grid with constant load. The various combination of irradiation and wind speed was applied. The second is hybrid PV/Wind connects to the grid with the load profile with the high irradiation condition occur at daylight and high wind speed occur at daynight.

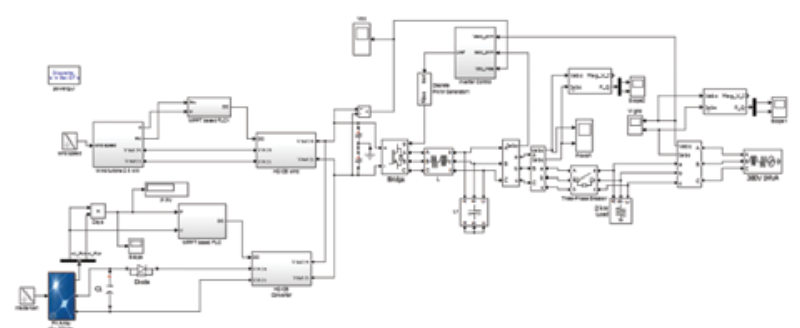

Fig. 14 Hybrid PV/Wind on 1MVA grid system Simulink model 
As a result, the following figure below shows the power output from the Hybrid PV/Wind Turbine system that connects to the grid both active and reactive power. The common DC bus voltage stay in constant due to irradiation and wind speed changes. Irradiation was drop from $1 \mathrm{~kW} / \mathrm{m}^{2}$ to $0.4 \mathrm{~kW} / \mathrm{m}^{2}$ and wind speed changes from $9 \mathrm{~m} / \mathrm{s}$ to $4 \mathrm{~m} / \mathrm{s}$.

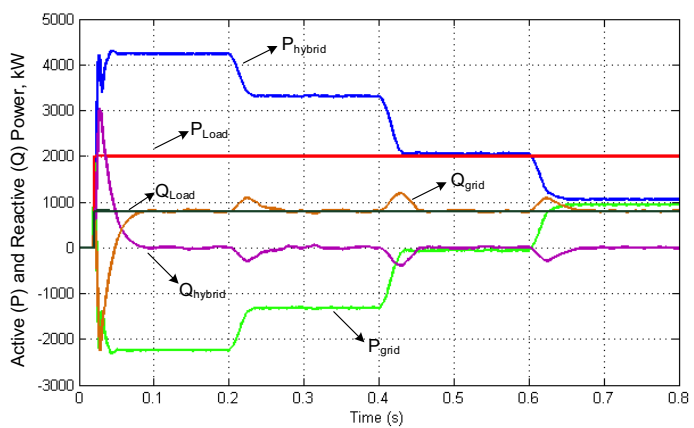

Fig. 15 Hybrid PV/Wind power delivered to the grid with constant load

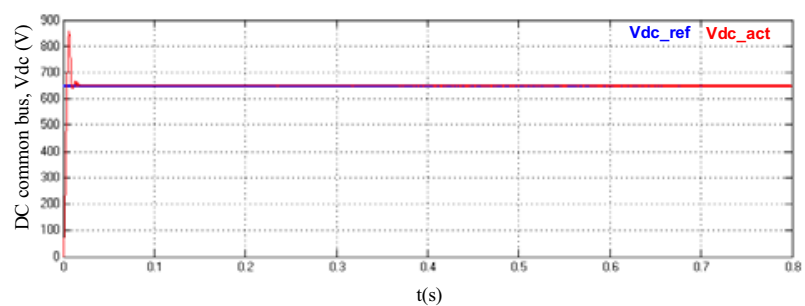

Fig. 16 Common DC bus voltage stay constant

Second, the hybrid PV/Wind was applied to the grid which has load profile, irradiation profile and wind profile. The blue line in the figure below shows the total amount power of the hybrid PV/Wind that injected to the grid as a result from irradiation and wind changes.

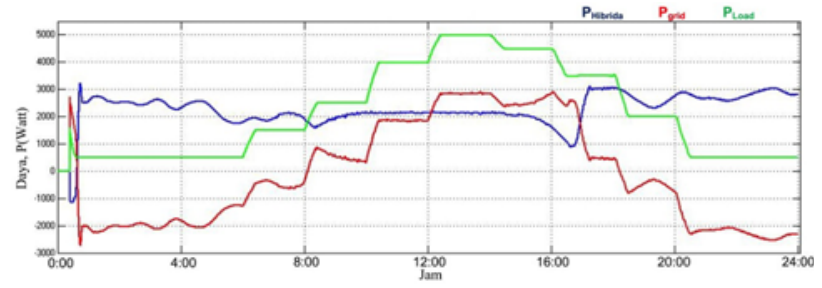

Fig. 17 Hybrid PV/Wind active power that injected to the grid in load profile condition

\section{Conclusion}

The conclusion from this proposed paper explained as follow:

1. The utilizing of HGICB in small scale hybrid system connected to grid could improve conversion effectiveness because it have high ratio conversion and wide input range.

2. Total installed capacity of hybrid system is $4.4 \mathrm{~kW}$ with DC voltage constant in $650 \mathrm{~V}$ without using storage device.

3. The utilizing Hybrid PV and wind turbine can reduce the power from existing conventional generating unit in utility grid system to supply the load.

4. The utilizing of fuzzy MPPT to arrangement of switching duty cycle in HGICB both in PV and Wind has error percentage low $(<2 \%)$. It's a fastreacting MPPT.

5. The utilizing of current control PWM inverter with synchronies reference theory could accelerate transient response time while hybrid system connected to grid utilities.

\section{References}

1. Abbasi, R. Improvement of the Integration of a GridConnected Wind-Photovoltaic Hybrid System. Electrical Engineering and Software Application (ICEESA) International Conference on, 2013

2. Soedibyo, Feby Agung P., Prof. M. Ashari, Control Design of Photovoltaic BPSX-60 Using Fuzzy Logic Controller for Low Voltage Grid. International Seminar on Intelligent Technology and Its Application, 2015

3. Narsa Reddy Tummuru, Mahesh K. Mishra. Integration of PV/Battery Energy Conversion System to the Grid with Power Quality Improvement Features, IEEE Transactions On Power Electronics, 978-14673-4569-9, 2013

4. Lakshman Rao S.P, Dr. Ciji Pearl Kurian, Dr. B.K.Singh, Athulya Jyothi V. Simulation and Control DC/DC Converter for MPPT Based Hybrid PV/Wind Power System, International Journal of Renewable Energy Reasearch Vol.4 No.3, 2014

5. Ping Yang, Jianping $\mathrm{Xu}$, A New Quadratic Boost Converter with High Voltage Step-up Ratio and Reduced Voltage Stress, IEEE International Power Electronics and Motion Control Conference-ECCE Asia, 2012

6. Ahmed Mohamed Abdel Moniem El-Sebani. Sensorless MPPT Technique for Grid Connected PMSG Wind Turbine, Thesis of Electrical and Control Engineering Arab Academy For Science and Technology and Maritime Transport, Egypt, 2014 